\title{
O desenvolvimento adulto do sujeito deficiente intelectual e a relação com a Educação para Jovens e Adultos (EJA): uma análise, a partir da perspectiva docente
}

The adult development of the intellectual disability subject and the relationship with education for young and adults (EJA): an analysis, from the perspective of teachers

El desarrollo adulto del sujeto deficiente intelectual y la relación con la educación para jóvenes y adultos (EJA): un análisis, desde la perspectiva docente

* Olga Mara Bueno

Graduada pela Universidade Estadual de Ponta Grossa, Ponta Grossa, Paraná, Brasil. olgamarabueno@gmail.com

** Rita de Cássia da Silva Oliveira

Professora doutora da Universidade Estadual de Ponta Grossa, Ponta Grossa, Paraná, Brasil. soliveira13@uol.com.br

Recebido: 01 de dezembro de 2017

Aprovado: 19 de agosto de 2018

\section{RESUMO}

Este artigo analisa a partir de perspectiva docente a influência das práticas pedagógicas inclusivas em uma escola de Educação para Jovens e Adultos (EJA), para o desenvolvimento do aluno adulto com Deficiência Intelectual Leve ou Moderada. O estudo se deu a partir de pesquisa bibliográfica e de pesquisa de campo junto a docentes que atuam nos anos finais do Ensino Fundamental e do Ensino Médio da EJA. Sustenta-se na Teoria Histórico- Cultural de Vygotsky, entendendo o sujeito adulto como um ser constituído socialmente, passível de desenvolvimento e influências do meio. Os dados apontam que a escola está buscando atuar sob os princípios da Educação Inclusiva, onde as práticas pedagógicas tendem a contribuir com o desenvolvimento social do sujeito adulto deficiente intelectual, sob uma abordagem da reconstrução do direito de estudar. No entanto, evidenciam a necessidade de conscientização do aluno e de seu grupo familiar para a vivência da adultez, e da efetiva atuação das redes que dão suporte às famílias. O estudo também suscita possibilidades para contrapontos e aprofundamento de estudos considerando o atendimento ao aluno com Deficiência Intelectual Leve ou Moderada que está na EJA e a vivência efetiva da cidadania, sobrepondo-se às acomodações históricas observadas socialmente na relação com a deficiência.

Palavras-chave: Educação; Deficiência; Desenvolvimento. 


\section{ABSTRACT}

This article analyzes from a teaching perspective the influence of inclusive pedagogical practices in a school for youth and adult education (EJA), for the development of the adult student with light or moderate intellectual disability. The study was made starting from a bibliographic and field research along with the faculty that act in the final years of middle and high school at EJA. It holds itself in the Cultural-Historical Theory of Vygotky, that understands the adult subject as a living being socially constituted,susceptible of environ mental development influences. The data points that the school is trying to act under the principles of inclusive education, where the pedagogical practice tend to contribute to the social development of the intellectual deficient adult subject, under a reconstruction of the right to study approach. However, they evidenced the need for the student awareness and his/her family group for the experience of adulthood, and the effective acting of the networks that give support to the families. The study also raises possibilities for counterpoints and deepening of the studies considering that it's at EJA and effective experience of citizenship, overlapping the historical accommodations socially observed in the relation with disability.

Keywords: Education; Disability; Development.

\section{RESUMEN}

Este artículo analiza desde perspectiva docente la influencia de las prácticas pedagógicas inclusivas en una escuela de Educación para Jóvenes y Adultos (EJA), para el desarrollo del alumno adulto con Deficiencia Intelectual Ligera o Moderada. El estudio se dio a partir de investigación bibliográfica y de investigación de campo junto a docentes que actúan en los años finales de la Enseñanza Fundamental y de la Enseñanza Media de la EJA. Se sustenta en la Teoría Histórico-Cultural de Vygotsky, entendiendo al sujeto adulto como un ser constituido socialmente, pasible de desarrollo e influencias del medio. Los datos apuntan que la escuela está buscando actuar bajo los principios de la Educación Inclusiva, donde las prácticas pedagógicas tienden a contribuir con el desarrollo social del sujeto adulto discapacitado intelectual, bajo un enfoque de la reconstrucción del derecho de estudiar. Sin embargo, evidencian la necesidad de concientización del alumno y de su grupo familiar para la vivencia de la adultez, y de la efectiva actuación de las redes que dan soporte a las familias. El estudio también suscita posibilidades para contrapuntos y profundización de estudios considerando la atención al alumno con Deficiencia Intelectual Ligera o Moderada que está en la EJA y la vivencia efectiva de la ciudadanía, sobreponiéndose a las acomodaciones históricas observadas socialmente en la relación con la discapacidad.

Palabras clave: Educación; Deficiencial; Desarollo.

\section{Introdução}

A atuação da escola sob a égide da educação inclusiva atribui relevância às práticas pedagógicas de acessibilidade curricular para os alunos com Deficiência Intelectual Leve ou Moderada que estão nos anos finais do Ensino Fundamental e Ensino Médio da 
Educação para Jovens e Adultos (EJA), como ações propulsoras de desenvolvimento à vida social desses sujeitos. Este trabalho problematiza essa relação, considerando perspectivas docentes frente às práticas que movimentam e o contexto de observação da vivência, relacionamento e proximidade com esses alunos em sala de aula.

$\mathrm{O}$ artigo discute os enfrentamentos identificados a partir e, além da sala de aula para a construção da identidade e desenvolvimento desses alunos como sujeitos adultos, com imposições e responsabilidades que a vida adulta impõe. Para isso, aponta que os sujeitos em estudo são alunos deficientes intelectuais leves ou moderados, a partir de definições clínicas descritas em laudos indicativos da deficiência apresentados pelas famílias à escola quando do ingresso, ancorando o presente estudo nas definições apresentadas no Manual Diagnóstico e Estatístico de Transtornos Mentais (DSM 5) elaborado pela Associação Americana de Psiquiatria (2014), e em orientações da Organização Mundial de Saúde (OMS), citadas por Ke e Liu (2015). Discorre sobre Educação para Jovens e Adultos, o histórico e a luta pelo direito de acesso e permanência à escola, conforme citações de Paula e Oliveira (2011) e sobre práticas pedagógicas na EJA sob a perspectiva da Educação Inclusiva, a partir de documentos da Secretaria de Estado da Educação do Paraná (2006), as Diretrizes Curriculares para a EJA e Diretrizes Curriculares para a construção de Currículos Inclusivos. O desenvolvimento do sujeito adulto é considerado a partir da Teoria Histórico - Cultural, com base na leitura de Vygotsky (1991), (1997) e em estudos de Lopes e Dias de Oliveira, que reforçam o entendimento do sujeito adulto deficiente intelectual como integrante do contexto histórico - cultural, ponderando sobre a atuação do grupo familiar e das redes de apoio sociais na formação e identidade desses sujeitos.

Utiliza-se dos estudos de Vygotsky para dar sustentação a constituição e definição do aluno deficiente intelectual que está na EJA, considerando - o como adulto, numa condição de inter-relacionamento do sujeito histórico-social com as implicações impostas pela deficiência e os fatores sociais que interferem na vivência da adultez.

\section{Educação para Jovens e Adultos (EJA): a reconstrução do direito de} estudar

Historicamente, conforme apontam as Diretrizes Curriculares da Educação para Jovens e Adultos (DCEs) do Estado do Paraná (2006a) a Educação para Jovens e Adultos no Brasil era entendida apenas como processo de alfabetização. $O$ conceito de educação 
http://dx.doi.org/10.5902/1984686X30203

para a continuidade e término da escolarização básica é uma proposta recente, o que significa avanços para superação de políticas educacionais segregatórias e excludentes.

Segundo Paula e Oliveira (2011, p.16) a educação com jovens e adultos no Brasil teve início na colonização com as práticas de catequização efetuadas pelos padres jesuítas que "na tentativa de aculturar os povos aqui existentes, trabalhavam com índios já adultos", deixando legados para um sistema de educação que nos séculos seguintes não recebeu atenção ou investimentos, gerando um contingente de analfabetos.

E assim, permaneceu por muito tempo, conforme destacam as DCEs para a Educação de Jovens e Adultos no Estado do Paraná (2006a, p.16) "durante quase quatro séculos observou-se o domínio da cultura branca, cristã, masculina e alfabetizada sobre a cultura dos índios, negros, mulheres e analfabetos." Somente no final do século XIX e início do século XX é que foram aprovados projetos de lei que tornaram a educação de jovens e adultos obrigatória, com o objetivo de aumentar o contingente eleitoral e atender aos interesses das elites

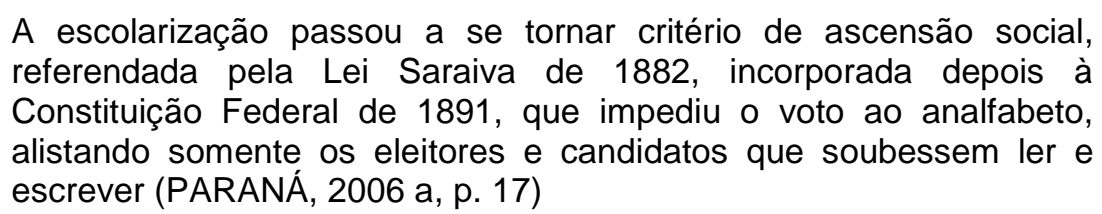

O analfabetismo segue sendo considerado um mal e políticas públicas educacionais efetivas voltadas para a EJA no Brasil, só serão observadas na década de 1940, conforme apontam Paula e Oliveira (2011, p.17) "a criação de políticas mais efetivas, começou a ocorrer somente a partir da década de 1940, período de crescente processo de industrialização e reconfiguração política". Seguindo nessa direção, a Constituição Federal de 1988 passa a garantir a oferta de Educação para Jovens e Adultos como modalidade específica da educação básica, "estabelecendo o direito à educação gratuita para todos os indivíduos, inclusive aos que a ela não tiveram acesso na denominada idade própria".

A diversidade pode ser entendida como a característica que define os sujeitos que constituem a EJA e nesse sentido, Paula e Oliveira (2011, p. 50) descrevem essa diversidade como: "etária (adolescentes, jovens, adultos, idosos); de gênero (homens, mulheres); étnica (negros, mestiços, indígenas, brancos); cultural (agricultores, pescadores, artesãos, operários)." Essas diferenças caracterizam os alunos jovens, adultos ou idosos, implicando diretamente nas práticas pedagógicas. 
$\mathrm{Na}$ Educação para Jovens e Adultos, o atendimento às pessoas com deficiência é garantido pela Política Nacional de Educação Especial na perspectiva da Educação Inclusiva, Brasil (2008, p. 12) de que em "todas as etapas e modalidades da educação básica, o atendimento educacional especializado é organizado para apoiar o desenvolvimento dos estudantes, constituindo oferta obrigatória dos sistemas de ensino", afirmando ainda que essa modalidade de ensino oportunize aos estudantes com deficiência possibilidades não só para a escolarização, mas também para o ingresso no mundo do trabalho e o desenvolvimento e participação social.

\title{
A deficiência intelectual e o aluno adulto deficiente intelectual
}

A Deficiência Intelectual é definida pela Associação Americana de Psiquiatria como um transtorno do desenvolvimento intelectual que se caracteriza por

\begin{abstract}
[...] déficits em capacidades mentais genéricas, como raciocínio, solução de problemas, planejamento, pensamento abstrato, juízo, aprendizagem acadêmica e aprendizagem pela experiência. Os déficits resultam em prejuízos no funcionamento adaptativo, de modo que $o$ indivíduo não consegue atingir padrões de independência pessoal e responsabilidade social em um ou mais aspectos da vida diária, incluindo comunicação, participação social, funcionamento acadêmico ou profissional e independência pessoal em casa ou na comunidade. (ASSOCIAÇÃO AMERICANA DE PSIQUIATRIA, 2014, p. 78)
\end{abstract}

Com relação ao adulto com Deficiência Intelectual, é possível afirmar que os apoios oferecidos e oportunidades de participação em atividades práticas do cotidiano, colaboram para avanços no desenvolvimento adaptativo desses sujeitos

\begin{abstract}
Em crianças mais velhas e adultos, o nível de apoio oferecido é capaz de possibilitar a completa participação em todas as atividades cotidianas e melhora na função adaptativa. As avaliações diagnósticas devem determinar se uma melhora nas habilidades de adaptação é resultado da aquisição de uma nova habilidade estável e generalizada (caso em que o diagnóstico de deficiência intelectual pode não ser mais apropriado) ou contingência da presença de apoios e intervenções ininterruptas (caso em que o diagnóstico de deficiência intelectual pode ainda ser apropriado). (ASSOCIAÇÃO AMERICANA DE PSIQUIATRIA, 2014, p. 80
\end{abstract}

Sob as condições pedagógicas que se constituem e se definem na escola, considerase o aluno deficiente intelectual aquele devidamente avaliado, com laudo diagnóstico descrito, onde consta a deficiência, que possuem incapacidade caracterizada por limitações significativas no funcionamento intelectual e no comportamento adaptativo, expresso nas 
http://dx.doi.org/10.5902/1984686X30203

habilidades práticas, sociais e conceituais, originando-se antes dos dezoito anos de idade. (PARANÁ, 2011).

Esses alunos podem apresentar algumas dificuldades que implicam em seu desenvolvimento, tais como: dificuldades na linguagem expressiva e compreensiva, no aprendizado (recepção, memória e estímulos visuais) e na capacidade de articular pensamento e ação, na localização espaço - temporal, comportamento infantilizado para faixa etária, dependência afetiva e constante de uma pessoa adulta, dificuldade para transpor a aprendizagem, baixa autoestima, dentre outros. No entanto, são passíveis de se desenvolverem e se posicionarem socialmente como adultos, conforme o grau de incapacidade intelectual, classificados de acordo com o coeficiente intelectual (QI).

Para a Organização Mundial da Saúde (OMS apud Ke e Liu, 2015), o grau de incapacidade condiciona e implica nas formas de atuação e crescimento que caracterizam a capacidade adulta.

No grau de Deficiência Intelectual Leve, faixa de coeficiente intelectual entre 50 a 70, a alfabetização é atingível e as habilidades de autoajuda, boa fala e trabalho semiqualificado são perfeitamente atingíveis. No grau de Deficiência Intelectual Moderado, coeficiente intelectual de 35 a 50, a alfabetização em alguns casos é atingível e as habilidades de autoajuda, fala em casa e trabalho não qualificado, com ou sem supervisão são atingíveis. Para os casos de Deficiência Intelectual Severa, QI de 20 a 35, atividades de autoajuda assistidas, fala mínima e tarefas domésticas assistidas são atingíveis e nos casos de Deficiência Intelectual Profunda, fala e atividades de autoajuda são algumas vezes atingíveis, alfabetização e capacidade de trabalho não são atingíveis.

\section{A teoria histórico-cultural e a relação com a deficiência intelectual}

A abordagem da Teoria Histórico- Cultural de Vygotsky traz importantes contribuições para o entendimento da formação do homem e da sua relação com o meio. Rego (2014, p. 93) diz que na Teoria Histórico- Cultural, organismo e meio têm funções recíprocas e que são as interações sociais que constituem o sujeito, o homem "é visto como alguém que transforma e é transformado nas relações produzidas em uma determinada cultura". Esse pensamento se sobrepõe a outras abordagens que entendem a constituição e desenvolvimento do homem determinados por condições inatas ou adquiridas. Para 
http://dx.doi.org/10.5902/1984686X30203

Vygotsky, o que ocorre "é uma interação dialética que se dá, desde o nascimento, entre o ser humano e o meio social e cultural em que se insere". (REGO, 2014, p. 93).

Os estudos da "Defectologia" de Vygostsky (1997) possibilitam o entendimento da deficiência dentro dessa relação do homem com o meio. Esse autor entende que a deficiência é uma condição, passível de desenvolvimento, se o sujeito for estimulado. A obra da "Defectologia" aborda os conhecimentos e as pesquisas de Vygostsky sobre a deficiência, sob a perspectiva da Teoria Histórica- Cultural. Sobre a Deficiência Intelectual, citada como "retardo mental", cabe a compreensão de que se deve estimular o aprendizado focado nas funções que o sujeito ainda não domina, que ainda não se encontram desenvolvidas, destacando o papel da mediação como fator preponderante para a aprendizagem.

\begin{abstract}
Acreditava-se há algum tempo que, pelo uso de testes, poderíamos determinar o nível de desenvolvimento mental no qual o processo educacional deveria se basear e cujos limites não deveriam ser ultrapassados. Esse procedimento orientava o aprendizado em direção ao desenvolvimento de ontem, em direção aos estágios de desenvolvimento já completados. (VYGOTSKY, 1991, p.60)
\end{abstract}

Os estudos apontaram que na prática, essa abordagem estava equivocada, ao não se considerar a influência do meio como fator atuante sobre o desenvolvimento desses sujeitos

\begin{abstract}
Estudos estabeleceram que as crianças retardadas mentais não são muito capazes de ter pensamento abstrato. Com base nesses estudos, a pedagogia da escola especial tirou a conclusão, aparentemente correta, de que todo o ensino dessas crianças deveria basear-se no uso de métodos concretos do tipo "observar - e - fazer". E, apesar disso, uma quantidade considerável de experiências com esse método resultou em profunda desilusão. (VYGOTSKY, 1991, p.60)
\end{abstract}

Dessa forma, a pessoa com Deficiência Intelectual deve ser estimulada para a construção do pensamento abstrato, considerando as situações vivenciadas no meio, que constituem e definem o sujeito. Esse é o papel que cabe à escola, como formadora e propulsora de desenvolvimento
Precisamente porque as crianças retardadas, quando deixadas a si mesmas, nunca atingirão formas bem elaboradas de pensamento abstrato, é que a escola deveria fazer todo esforço para empurrá-las nessa direção, para desenvolver nelas o que está intrinsecamente faltando no seu próprio desenvolvimento. (VYGOTSKY, 1991, p.60)

Sob as concepções de zonas de desenvolvimento defendidas nos estudos de Vygostsky (1991), o aprendizado pela pessoa deficiente intelectual, pode ser estimulado na medida em que se compreende a zona de desenvolvimento proximal, como as 


\section{http://dx.doi.org/10.5902/1984686X30203}

possibilidades de se permitir que o aprendizado se adiante ao desenvolvimento do sujeito, caracterizando o que ao autor define como escola prospectiva, "o nível de desenvolvimento real caracteriza o desenvolvimento mental retrospectivamente, enquanto a zona de desenvolvimento proximal caracteriza o desenvolvimento mental prospectivamente". (VYGOTSKY, 1991, p. 58)

De acordo com Rego (2014, p.107) essa compreensão é fundamental no espaço escolar, pois possibilita o entendimento da relação sujeito e aprendizado como aquela que "necessita da intervenção, da colaboração de parceiros mais experientes da cultura para se consolidarem e como consequência ajuda a definir o campo e as possibilidades da atuação pedagógica". Nesse cenário ganha destaque a atuação da escola e o espaço do professor, como elemento mediador.

Para a Teoria Histórico - Cultural, a deficiência é entendida sob o aspecto das interações sociais, que possibilitarão ao indivíduo o seu desenvolvimento de uma forma diferente, não apenas em função de sua limitação biológica, mas dos estímulos proporcionados pelo meio histórico social.

\section{O estudo e seu percurso}

O presente estudo surge de uma necessidade crescente observada na prática do trabalho da Sala de Recursos Multifuncional Tipo I na EJA, em relação ao desenvolvimento do sujeito adulto deficiente intelectual leve ou moderado que frequenta a EJA, não só na sala de aula, quando a preocupação é do docente em relação ao aprendizado, mas também do próprio aluno, quando se questiona sobre o que fazer fora da escola. Procura entender em que medida o aprendizado escolar pode ser significativo ao aluno e qual a relação para mudanças em sua trajetória como um sujeito histórico social, problematizando o que fazer além da escola, que espaços sociais a frequência à escola lhe permite ocupar. Dessa forma, este estudo pode ser caracterizado como pesquisa de campo, de natureza qualitativa, que exigiu inicialmente, uma pesquisa bibliográfica.

Para Gil (2002, p. 44), a pesquisa bibliográfica é "desenvolvida com base em material já elaborado, constituído principalmente de livros e artigos científicos", e quase todos os estudos exigem esse tipo de trabalho. A pesquisa de campo é "desenvolvida por meio da observação direta das atividades do grupo estudado e de entrevistas com informantes para captar suas explicações e interpretações do que ocorre no grupo." (GIL, 2002, p. 53) 
Os dados foram obtidos com dez professores, identificados neste trabalho como P1 a P10, que atendem alunos com Deficiência Intelectual em suas disciplinas na EJA, em articulação com o trabalho da Sala de Recursos Multifuncional, no Centro Estadual de Educação Básica para Jovens e Adultos (CEEBJA) Professor Ignácio Alves de Souza Filho, em Jaguariaíva, PR.

Os alunos deficientes intelectuais nesse contexto somam um total de dezesseis, sendo sete no Ensino Médio e os demais nos anos finais do Ensino Fundamental, frequentando as diferentes disciplinas e a Sala de Recursos Multifuncional. Desse total, apenas um apresenta laudo indicativo de Deficiência Intelectual Moderada, os demais são casos de Deficiência Intelectual Leve. De acordo com Ke e Liu (2015), na Deficiência Intelectual Leve a alfabetização é atingível e as habilidades de autoajuda, boa fala e trabalho semiqualificado são perfeitamente atingíveis, sendo que na Deficiência Intelectual Moderada, a alfabetização em alguns casos é atingível e as habilidades de autoajuda, fala em casa e trabalho não qualificado, com ou sem supervisão são atingíveis.

Os dados sobre a deficiência dos alunos em estudo constam em relatórios clínicos, elaborados por médicos e, ou psicólogos, apresentados pela família, pelo aluno, quando do ingresso na Educação para Jovens e Adultos, ou ainda enviados por escola de Educação Básica na Modalidade de Educação Especial, onde o aluno foi alfabetizado ou cursou os anos iniciais do Ensino Fundamental. São sujeitos que se encontram na faixa etária entre 16 e 45 anos, sendo que sete deles estão inseridos no mercado de trabalho. Dos nove alunos que não trabalham, seis recebem benefício do Instituto Nacional de Previdência Social (INSS), o Benefício Assistencial ao Idoso e à Pessoa com Deficiência (BPC), que é a "garantia de um salário mínimo mensal ao idoso com 65 anos ou mais ou à pessoa com deficiência com impedimentos de natureza física, mental, intelectual ou sensorial de longo prazo (que produza efeitos pelo prazo mínimo de 2 anos)." (BRASIL, 2017). Para este trabalho, foram considerados dados a partir da perspectiva de professores que trabalham não só com os alunos, mas atuam junto às famílias, obtendo informações através de observações e de relatos formais e informais, sobre a atuação e condição social desses sujeitos, ou seja, como é a vivência fora da escola, quais as perspectivas que mantêm para a escolarização, e em que medida as ações da prática escolar estimulam o desenvolvimento social do adulto deficiente intelectual. 


\section{Os resultados}

A pesquisa junto aos docentes foi realizada a partir de um questionário aberto com indagações sobre as práticas pedagógicas realizadas na EJA e a relação com o desenvolvimento do sujeito adulto deficiente intelectual, conforme descrito a seguir, no qual, baseando-se nos estudos da Teoria Histórico- Cultural de Vygotsky é possível afirmar que a escola é "(...) uma importante instância mediadora na construção dos significados sobre si e sobre o mundo, assim como nos aspectos formativos necessários na transição para a vida adulta e inclusão social dessas pessoas”. (DIAS; LOPES DE OLIVEIRA, 2013, p.180). Com base nessa afirmação, e na sua prática pedagógica na Educação para Jovens e Adultos, de que forma a escola, como instância mediadora, direciona o adulto deficiente intelectual para "a construção de significados sobre si e sobre o mundo", considerando o que "está intrinsecamente faltando" no desenvolvimento desses sujeitos.

Dessa forma, procurou sistematizar o entendimento do professor sobre a inclusão dos alunos com Deficiência Intelectual nos anos finais do Ensino Fundamental e Ensino Médio da EJA e a relação das práticas que movimentam para o desenvolvimento desses alunos como sujeitos histórico-sociais, a partir da relação que mantêm com as famílias e o relacionamento social, considerando aspectos sociais como trabalho, atividades da vida adulta: ir às compras, pagar contas e atividades de lazer.

Nós, professores estamos estudando mais, buscando conhecimentos para proporcionar atendimento adequado aos alunos com Deficiência Intelectual, trabalhando cada vez mais distantes da infantilização desses sujeitos. (P4)

Temos procurado entender como esse aluno aprende e formas de estimulá-lo a maior participação na escola e na vida, promovendo adaptações no currículo e estimulando-os a participação social, para que o estar na escola atribua significados à vida, que tenham perspectivas do que fazer após a escola, que eles possam continuar estudando, trabalhando, produzindo, vivendo, se divertindo, sendo felizes [...] (P1)

É um grande avanço a presença desses alunos na escola e ter uma escola preocupada com questões acadêmicas, de ensino e aprendizagem, pois esses alunos, muitas vezes ao longo da vida, por diferentes fatores sociais, que agora estão sendo superados, não estavam na escola, frequentando espaços que não conseguiam suprir suas necessidades de aprendizado e desenvolvimento. (P6)

A escola é entendida como um espaço para fortalecimento dos vínculos sociais e de ampliação de perspectivas para a vivência da cidadania, mas os enfrentamentos cotidianos 
na relação Deficiência Intelectual e a ocupação do espaço social, ainda é evidente "Na escola, nós trabalhamos os conteúdos, função inerente à escola, e procuramos estimulálos à participação nas atividades da vida adulta, mas entendemos que a sociedade ainda está fechada ao desenvolvimento dessas pessoas". (P3)

\begin{abstract}
A escola trabalha com adaptações, procura tornar acessível o currículo a que 0 aluno tem direito. Mas isso, não significa desenvolvimento social para eles. Muitas vezes observamos que eles permanecem desocupados fora da escola, seja por proteção da família (por causa do benefício que recebem), ou porque não encontram o que fazer (...) os que já trabalham, observamos que têm vida social mais desenvolvida, trabalham, administram o que ganham, em determinadas situações em conjunto com a família, entendem a relação dinheiro e poder de compra, viajam, saem mais de casa, namoram e tem até aluna casada e com filho, uma família constituída (P8)
\end{abstract}

Há no argumento desses professores, a preocupação com a necessidade de adaptação curricular, entendida como um fator importante para a movimentação de práticas pedagógicas que impulsionem o desenvolvimento do aluno na escola. Nessa mesma proporção, há a preocupação com o desenvolvimento desse aluno fora da escola, para o enfrentamento de barreiras sociais, entendendo a família como o principal agente mediador nesse contexto

\begin{abstract}
A escola está evoluindo no atendimento ao aluno deficiente intelectual. Temos as Salas de Recursos, o trabalho de parceria com a Educação Especial e fazemos adaptação de currículo, mas ainda existe uma forte necessidade de maior conscientização e participação das famílias, principalmente quando trabalhamos com os adultos. (P9)
\end{abstract}

Nós procuramos fazer a nossa parte, na busca do desenvolvimento dos alunos com Deficiência Intelectual, mas não depende só da escola. [...] (P10)

O trabalho de conscientização do grupo familiar e do próprio estudante sobre as possibilidades de atuação e vivência efetiva da cidadania é encarado como um desafio. É o reflexo de um cenário, onde a família e a sociedade ainda não têm estrutura para orientar e promover os encaminhamentos para o sujeito deficiente intelectual adulto, sendo que a

[...] a família não se posiciona, não busca, não luta por mais oportunidades, e os alunos também, na maioria dos casos, não tem consciência também, não sentem necessidade de serem mais atuantes socialmente. Fazemos o que é possível, mas é difícil fazer essa articulação com as famílias, ainda mais aqui que já são alunos adultos. (P10) 


\section{Os enfrentamentos: uma análise}

Os docentes entendem que as práticas pedagógicas realizadas na escola procuram atender as necessidades do aluno, à medida que os professores buscam formação para o entendimento do que são adaptações curriculares e de como movimentá-las na sala de aula, procurando atender às implicações da Deficiência Intelectual.

As Diretrizes Curriculares da Educação Especial para a construção de currículos inclusivos no Estado do Paraná defendem que a efetivação de práticas inclusivas deve envolver a organização do processo de aprendizagem, por

\section{[...] meio da flexibilização e adaptações curriculares - de conteúdos, métodos, avaliação - de modo a contemplar a participação de todos os alunos, considerando seus conhecimentos prévios, suas necessidades linguísticas diferenciadas e o contexto social (PARANÁ, 2006 b, p.49)}

Ao assumir essa posição de educação inclusiva, a escola se coloca sob a visão prospectiva de escola, aquela defendida por Vygotsky (1991) como uma escola propulsora de aprendizagens, que impulsiona o aluno com Deficiência Intelectual a ir além, que ao se trabalhar o conteúdo acadêmico orienta o aprendizado em direção aos estágios que precisam ser desenvolvidos e que serão alcançados pela mediação, considerando-se todas as variáveis, os conhecimentos prévios, e as questões sociais. As Diretrizes Curriculares da Educação de Jovens e Adultos (Paraná, 2006a, p. 27) afirmam que "o papel fundamental da construção curricular para a formação dos educandos desta modalidade de ensino é fornecer subsídios para que se afirmem como sujeitos ativos, críticos, criativos e democráticos."

Nesse cenário, na escola há a necessidade de resgate do apoio e conscientização, não só da família, mas também do próprio aluno sobre o seu papel como sujeito histórico social. A escola tem se preocupado em atender os seus sujeitos, considerando-se as suas especificidades pedagógicas. Mas também, é evidente a preocupação com as especificidades sociais, ponderando em que aspectos a escola pode se tornar significativa, se não houver mudanças de paradigmas sociais, de rompimento de barreiras que a família ou o próprio sujeito deficiente intelectual coloca, de acomodação frente às dificuldades cotidianas e submissão à carência de oportunidades sociais, dentro de uma complexa atuação para prática da cidadania.

Os enfrentamentos são diversos, mas o primeiro e principal é a conscientização do sujeito e da família do seu papel social e da sua capacidade argumentativa e produtiva que os definem como pessoas, como cidadãos. São debates que transcendem a sala de aula, 
o espaço da escola, mas que são inevitáveis que se iniciem nesse contexto, senão as práticas pedagógicas se descaracterizam e perdem o seu caráter de atuação, como propulsoras de aprendizado e desenvolvimento para esses sujeitos.

A ausência de enfrentamento social, de convivência e inter-relacionamento é condição para o fortalecimento da deficiência, conforme afirmam Dias e Lopes de Oliveira, sob a perspectiva da Teoria Histórico-Cultural que

\begin{abstract}
No caso da pessoa com deficiência intelectual, fatores como a exposição empobrecida aos bens culturais, suporte sócio afetivo impróprio e processos pedagógicos inadequados favorecem a emergência do defeito secundário e o sentimento de deficiência como condição debilitante. (DIAS; LOPES DE OLIVEIRA, 2013, p. 176)
\end{abstract}

A Organização Mundial de Saúde (OMS) reforça a importância do apoio da família ao sujeito deficiente intelectual e da atuação das redes que dão suporte às famílias como condição para o desenvolvimento, envolvendo pais e outros membros da família, para que não se sintam sobrecarregados e saibam como agir, "a OMS sugere que o apoio à família precisa incluir comunicação do diagnóstico e informação sobre ele, apoio emocional, aconselhamento e treinamento familiar, envolvimento nas decisões de cuidados de saúde e cuidados continuados" (KE; LIU, 2015, p. 22)

\title{
Considerações Finais
}

Os estudos da Teoria Histórico- Cultural permitem entender o aluno com Deficiência Intelectual Leve ou Moderada que está nos anos finais do Ensino Fundamental e do Ensino Médio da EJA como um ser social, em constante interação com o meio. A Deficiência Intelectual deve ser entendida como uma condição que limita, mas não impede o desenvolvimento. Nos estudos da "Defectologia", (VYGOTSKY, 1997) o autor diz que o sujeito se constitui como orgânico e social, que realiza trocas no meio, que desenvolve um sistema de compensação das limitações orgânicas e que aprende pela mediação.

Nesse cenário, o professor é visto como mediador do aluno ao currículo. As adaptações curriculares são essenciais para avanços desses alunos na Educação para Jovens e Adultos. O acesso ao currículo, o avanço no processo de escolarização tem que se tornar significativo, influenciar na mudança de paradigmas e superação de antigas concepções sociais quanto ao desenvolvimento adulto, como o estereótipo de uma vida tutelada. 
Enfatiza-se que na escola, as práticas pedagógicas devem contribuir para a conscientização do aluno adulto quanto à construção de conhecimentos e significados sobre si e sobre o meio, sobre a importância das trocas sociais que efetiva como condições para o enfrentamento das situações que interferem no seu desenvolvimento como sujeito adulto. Este pressuposto abre possibilidades para contrapontos e aprofundamento de estudos que considerem o atendimento ao aluno deficiente intelectual na EJA e a vivência efetiva da cidadania, sobrepondo-se às acomodações históricas identificadas na relação com a deficiência.

\section{Referências}

ASSOCIAÇÃO AMERICANA DE PSIQUIATRIA. DSM - 5. Manual Diagnóstico e Estatístico de Transtornos Mentais. Trad. Maria Inês Corrêa Nascimento, et al. Revisão técnica Aristides Volpato Cordioli, et al. Porto Alegre: Artmed, 2014.

BRASIL. Benefício da Prestação Continuada ao Idoso e à Pessoa com Deficiência (BPC). Previdência Social. 2017. Disponível em: <http://www.previdencia.gov.br/servicos-ao-cidadao/todos-os-ervicos/beneficioassistencial-bpc-loas/>. Acesso em 06/08/2017.

BRASIL. Ministério da Educação. Conselho Nacional da Educação. Diretrizes Nacionais para a Educação Especial na Educação Básica. Parecer CNE/ CEB n. 17/2001. Brasília, 2001.

DIAS, Sueli de Souza; LOPES, Maria Claudia Santos Lopes de C. Deficiência Intelectual na perspectiva Histórico-Cultural: contribuições ao estudo do desenvolvimento adulto. Revista Brasileira de Educação Especial, Marília, v.19, n. 2, p. 169-182, abr./jun., 2013.

GIL, A. C. Como elaborar projetos de pesquisa. São Paulo: Atlas, 2002.

PARANÁ. Secretaria de Estado da Educação. Diretrizes da Educação de Jovens e Adultos. SEED/SUED. Curitiba, 2006 a.

PARANÁ. Secretaria de Estado da Educação. Diretrizes Curriculares da Educação Especial para a construção de currículos inclusivos. SEED/SUED. Curitiba, 2006 b.

PARANÁ. Secretaria de Estado da Educação. Instrução n. 14/ 2011- SEED/ SUED. Curitiba, 2011.

PAULA, C. R.; OLIVEIRA, M. C. Educação de Jovens e Adultos: a educação ao longo da vida. Curitiba: IBPEX, 2011. 
REGO, T. C. Vygotsky: uma perspectiva histórico-cultural da educação. Petrópolis: Vozes, 2014.

KE X; LIU J. Deficiência Intelectual. In Rey JM (ed), IACAPAP e-Text book of Child and Adolescent Mental Health. Edição: Dias Silva F. Tradução: Soares, I. F. Z.; Cavalcante, R. R. V.. Genebra: International Association for Child and Adolescent Psychiatry and Allied Professions, 2015. Disponível em: <http://iacapap.org/wpcontent/uploads/C.1-Intelectual-disabilities-PORTUGUESE-2015.pdf.> Acesso em: 27 set. 2016.

VIGOTSKY, L. S. Formação social da mente. São Paulo: Ed. Martins Fontes Ltda, 1991.

VIGOTSKY, L. S. Obras escogidas: Fundamentos de Defectología. Tomo V. Trad. Lic. Ma. Del Carmen Ponce Fernández. Habana: Editora Pueblo y Educación, 1997.

\section{Correspondência}

Olga Mara Bueno - Universidade Estadual de Ponta Grossa (UEPG) - Campus de Uvaranas. Av. General Carlos Cavalcanti, 4748, CEP: 84030-900, Ponta Grossa, Paraná, Brasil.

This work is licensed under a Creative Commons Attribution-NonCommercial 4.0 International (CC BY-NC 4.0) 